It will naturally be asked, How do the electrical currents act physiologically so as to cause the improvement as seen in this class of case? Psychical effects may be produced at times by these methods, as may happen in every other form of treatment. But improvement and care must in a series of cases be due, as in other methods, to powerfal therapeatical effects.

In cases in which the blood pressure is high, as I have already mentioned, the effect of reduction of arterial tension may in itself produce the result. In the use of electrical machines there is always a large amount of ozone generated, and it is not impossible that the inhalation of this gas for half an hour at a time may have some power of improving the patient's condition.

D'Arsonval and others have demonstrated increased tissue changes, more rapid reduction of the oxyhaemo. globin in the blood and increased elimination of waste products in the urine. Not only the sympathetic nerves controlling the vasomotor system, bat also those controlling the secretory, the thermogenic, and the peristaltic functions, are stimulated. There is a profound action on the protoplasm of cells everywhere, increasing their chemical changes. Usually an increased amount of urea is excreted, attended by a disappearance of uric acid showing the oxidation of nitrogenous material. It is said that the output of $\mathrm{CO}_{2}$ is sometimes increased from 17 to 37 litres an hour, and that there may be an increase in heat projuction from 79 to 127 calories an hour.

\section{SIMULATED DISEASE}

\section{OCCURRING IN PERSONS OF HYSTERICAL OR NEUROTIC TEMPERAMENT.}

By JOHN EWENS, L R.C.P.LOND., L.R C.S.EDIN., CONSULTING SURGEON TO THE BRISTOL ROYAL HOSPITAL FOR WOMEN AND CHIIDREN.

THE very interesting case of "dermatitis artefacta" reported by Dr. Adamson in the Journal of Jaly 2nd, 1910, recalls to my memory some cases occurring in a considerably long practice which have, I think, a practical bearing on the perplexing difficulties frequently experienced by most medical men in the treatment of certain anomelous cases, which from peculiar family or other circumstances, where the patient or relatives have reasons for simulating indisposition, and from motives of shame or false delicacy wish to conceal the tricks practised, thereby involving the practitioner inexperienced in such matters in mach trouble, fearing to give offence to relatives, therefore hesitating to express an opinion as to the fraud or unworthy motive on the part of the patient. It requires considerable moral courage on the part of the medical man to face the difficulty, and it is always necessary to guard oneself at every point to avoid hinting at a suspicion which may prove unfounded. A mistake would almost certainly involve the loss of the patient, and possibly ruin the prospects of a young practitioner. Two of the following cases (Nos. II and III) will illastra te the difficulty; but having once clearly and satisfactorily to oneself, from irrefutable evidence, proved the nature of the case, no hesitation should be felt as to the duty of prompt and decisive action. The natural reluctance to say anything which may cause unpleasant feelings between members of a family, or a rapture of the proper relations which should exist between a medical man and his patients, may well cause hesitation in forcing home his suspicions as to fraud or other unworthy motive; but in this as well as all other professional relations, the trite maxim, "Honesty is the best policy," should gaide the members of our noble profession, and will in the end bring most credit, as well as a clear conscience in the faithful performance of daty. I trust the report of the following cases may be helpfal to my younger and possibly less experienced professional brethren, and act as a guide to them in dealing with cases involving delicacy and accuracy in diagnosis.

CASE I.-The first case occurred in my very early practice more than fifty years since, and at this distance of time exact details are wanting, bat the main facts still remain impressed forcibly on my mind. An unmarried womsn, aged 30 years, of healthy family, after an easy extraction of a lower molar tooth complained of stiffness of the jaw and inability to masticate properly and swallow any solid food. The stiffness steadily increased, efforts to force the jaw open by wedges absolutely failing. Being of a neurotic and anaemic temperament, tonics, iron, nax vomica, etc., were freely administered with aperients, mild electrical shocks were frequently given, without $\epsilon$ ffect. No solid food was taken, but she freely partook of fluid nourishment. In order to discover any impediment to opening the mouth I placed her fully under chloroform, and thus established the absence of ossific or other mischief about the joint, but as she was emerging from anaesthesia, a series of hystero-epileptic attacks occurred, lasting for two hours, effectually preventing my repeating the experiment.

The next phase of the complaint presented itself in the form of pseudo-laryngitis, apparently originating in the form of an ordinary cold, resulting in loss of voice, with occasional spasmodic breathing, the patient generally speaking in a low voice or whisper. This continued for many years, in fact, for the twenty.five years during which I had the opportunity of knowing ber personally. She never, I believe, thoroughly recovered her voice.

The next development was simulated peritonitis with obstinate constipation, easily diagnosed as another form of the hysterical nature of the case. It was followed by retention of urine, requiring the ase of the catheter three times daily. On leaving the village to reside at a distance of three miles, I explained that I could not possibly give the necessary attention, and that I would teach her mother to use the catheter. She shortly passed urine voluntarily, and no further trouble of that kind occurred, conclusively proving the nature of the case. The next manifestation was an attack of apparent apoplexy. I was hastily summoned to her early one morning, and found her surronnded by weeping relatives, who said she had an apoplectic fit. She lay passive, her eyes partially open, pupils somewhat dilated, breathing normal, no stertor. no power to swallow fluids when placed in her mouth. The parents had found her thus early in the morning, and could not account for the attack, as she had been as usual daring the previous day, and went to bed well. Reflex movements of the legs were totally absent, tickling the soles of the foet eliciting no response. (This was the more forcibly impressed upon me as I went from her house to see a young woman actually dying of apoplexy in whom the reflex was very marked.)

My previous experience of the case led me to take a very optimistic view, and in a very decided and lond tone I told the parents, who at the time thought me very unkind, that they need not be troubled, as I felt sure she would quite recover within twenty-four hours. I have no doubt she heard me, and was influenced by my very decided manner and opinion. Next morning all the symptoms had disappeared, and she was soon as well as usual. I am not aware that any serious manifestation of hysteria ever occurred afterwards. This case was extremely difficalt to explain, no adequate motive existing, and nothing material could be gained by imposition except the incident of retention of urine, which is no doubt often due to a perversion of the moral faculties in hysterical young women, and ceases when unable to get a catheter passed. The parents were of the labouring class, and not likely to encourage deception. The uterine functions were normally performed.

CASE II -A young gentleman, aged 16, was brought to mo complaining of gastric trouble, with pain attributed to liver disease. It was stated that an uncle or grandfather had suffered from cancer of the liver, but of this there was no definite evidence. He was the son of a farmer in good position and easy circumstances. He had refused for some time to take food and eat as the other members of the family, yet did not lose flesh or show any appreciable signs of disease. He was ordered milk diet, but declared he could not take it. His home being at a large dairy farm, milk was easily obtained, and, failing emasiation or other signs of disease, I had no doubt that he secretly got access to the dairy, but I could not prove it. Home treatment being useless for obvious reasons, I suggested his retarning to school in Bristol ander my care, and judicious surveillance. Convinced that he was only pretending not to be able to take food, I took the mistress of the school into my confidence, telling her my suspici ons. I ordered 
him a plentiful supply (3 pints) of new milk with Liebig's extract of meat in sufficient quantity to disguise the milk. This he took for a considerable time, but no meat or other diet. I also gave him peppermint water to make him think he was taking medicine. After three or four weeks he got tired of the disguised milk, and I told him that as soon as he would take the ordinary food he should give it up gradually in proportion as he took meat. This was gradually done, and he soon regained the ordinary habits of living and got rid of his foolish idea of liver disesse, and remained quite well.

CASE III-A sister of the last case, aged about 13 years. A healthy looking girl. I was consalted about her for a supposed disease of the kidney. The friend accompanying her brought me some urine heavily laden with a yellowish precipitate resembling lithates, which was partially soluble in nitric acid, with slight effervescence. From the first I strongly suspected fraud, but as she had been under the care of another practitioner I exercised caution; but in a short time I felt sure she was trying to deceive me. Having gained the confidence of her governess, I told her my suspicions, instructing her to send me by post two specimens of arine-one passed under her supervision and kept by her, the other passed by the girl and left under her own care. I instructed the governess not to tell the mother of my suspicions. Then the fraud became clear. I received the two specimens. No. I perfectly normal; No. 2 "treated" by the girl herself, laden with deposit. I then requested the mother to bring the girl herself, with a specimen of the urine passed and dealt with by the girl herself, which presented the same appearance as that referred to as No. 2. Having made an excuse for sending the girl out of the room, I told the mother what I sus. pected. Of course she was very much annoyed, but I reasoned with her, and showed her the importance from a moral point of view, and requested to be left alone with the girl, when I kindly but forcibly challenged her as to fraud. At first she denied, but I persisted, and telling her if she told me the trath she should not be punished, and pointing out the evil of her conduct, and convincing her that I knew the trick, she confessed that she was in the habit of scraping the wall of her room, and putting the powder in the urine. Nothing bat full determination on my part would havesolved the mystery. The motives influencing the brother and sister are very diff calt to explain or understand, there being apparently nothing to be gained by their conduct, unless a morbid desire to create or excite sympathy, with a perverted moral sense, be accounted sufficient explanation for such extraordinary conduct.

CASE IV. - The next osse is evidently one of decided imposition for the purpose of gaining sympathy and extort. ing charity, and imposed for a long time on several persons who visited the woman. A delicate-looking woman, subject to a chronic cough, commenced spitting a coloured fluid, representing that she coughed it up. For a time I was deceived, but fortunately I detected some fine filaments of a pink appearance, and on carefal examination these were found to be small bits of pink cotton, cat up very finely, which bad been chewed, and the coloured saliva was then expectorated as blood!

CASE v.-Some years since, when surgeon to the Children's Hospital in this city, a practitioner told me of a curious case, and said be would like me to seo it in consultation, and it was partially arranged, but not carried out. He told me the child, aged about 12 yeare, was unable to walk or stand. From his description I sug. gested it was a case of hysteria. I did not then see the child, but understood that her mother had taken her to see a "specialist" in London (unfortunately, I believe, without any letter of explanation from her medical attendent), who, doubtless gaided only by the statements of the mother, probably not quite accurate, gave the opinion that she was suffering from some spinal affection, and ordered perfect rest in a special apparatus, to prevent motion. After some months, as no benefit was derived, I was asked to take the child into the hospital, and did so. On the day after admission I spoke to the child, and taking her little hands in mine, gently raised her into a sitting position, although she positively asserted that she could not sit up. I then got her round, still sitting, and taking down the side of the cot, got her to let her legs dangle for a few minutes. Next day I got her to stand on the flnor, still holding her, and the following day got her holding the rails of the cot (one on either side) to walk a few paces. The next day she made further progrese, and on the fourth day she walked, assisted by the nurse and myself, across the ward; on the fifth day she walked a short distance alone, and the following week she was discharged quite well.

I presume it has frequently fallen to the lot of practitioners to meet with cases of strong robust men, in whom not a shadow of pretence could be traced, who after long confinement to bed, have felt quite unable to stand. One such occurs to my mind. A strong healthy farmer, energetic and active, was sufforing from a painful attack of gouty lumbago, the inflammation extending to the eacroiliac synchondroses. The pain was so severe that for a fortnight movement in bed was intolerable, even to the extent of raising the arms to the head. At the end of three weeks he could sit out of bed, and I soon endeavoured to get him to stand. At first he declared this impossible, but, seated by the side of an old. fashioned four-poster bedstead, I got him to grasp one of the posts, and then raising his other hand grasping. it a little higher, and gradually progressing each hand higher than the other, at last got him into the erect posi. tion, at which he was greatly surprised. I then suggested he might, with assistance from his wife and myself, walk a few steps. This he at first ridiculed, bat, nothing daunted, I encouraged him to walk across the room. This being accomplished, he walked back leaning on my arm and using a walking-stick. I shall never forget his surprise; at first he thought I was cruel to suggest his making the effort. There could not possibly be any motive in his reluctance, but evidently his will power was. so seriously deteriorated by long inaction that nothing buta stronger will than his own could have urged him to make the effort. The late Sir Benjamin Brodie waspeculiarly successtul in inducing by moral suasion and determined will young hysterical persons to make a successful effort to leave the wall against which he or she was placed and walk to him, thus overcoming the weak nerve power by a stronger influence. Mental impressions have much to do with recovery after illness, and it is frequently more difficult to induce a patient to get out of bed after an attack of fever or other debili. tating illness than to persuade him to go to bed at the commencement. The treatment of some forms of chronicaterine disease is particularly difficult on account of the tendency to yield to mental lassitude and ennui. Of course, displacement and actual disease must be taken fally into consideration.

\section{EUCALYPTUS OIL POISONING.} BY

W. E. FOGGIE, M.A., M.D.,

PHYSICIAN FOR DISEASES OF THE SKIN, DUNDEE ROYAL INFIRMARY ; LECTURER, DISEASES OF THE SKIN, ST. ANDREWS UNIVERSITY.

CASRS of poisoning by oil of eucalyptus are so infrequentthat any individual experience seems worthy of record. The case in question is as follows:

A boy of 6, who had occssionally been in the habit of getting a drop or two of eucalyptus oil on sugar, was given by mistake a teaspoonful of the same. This was about 6 o'clock one evening. About 8 he had his usual light supper, and within two hours thereafter abdominal pain and severe vomiting set in. The vomiting continued without cessation of any length and diarrhoea soon became marked. By 11 o'clock the boy became drowsy, and when he was seen about this time he was semi-comatose. He was pale and collapsed, with a small but not very quick pulse. The muscles generally were flaccid. The pupils were medium in size and equal. The conjunctival reflex was not quite abolished. The tendon reflexes were present and were not exaggerated. There was no congh and the breathing was shallow. He could be roused by very vigorous slapping of the fac $\theta$, but each time he looked dazed. Every time he was wo water, which consisted of mucus and watery material, had a matter, which consisted of mucus and watery material, had a strong smell of eucalyptus oil. After two or three hours of external stimulation very much along the lines usually adopted for opium poisoning, the heavy comatose condition appeared to pass off, and the child was allowed to sleep. He slept well and next morning, beyond being a little tired, was quite himself again. The bresth had a smell of eucalyptus oil for three days. There was never any irritation of the urinary tract. In brief, the poison showed itself by gastro-intestinal irritation and cerebral paresis. 